\title{
PENGARUH PENAMBAHAN SERBUK SERASAH LAMUN (SEAGRASS) TERHADAP KUAT TEKAN DAN ABSORBSI AIR ECO-BATAKO
}

\author{
R. Bekti Kiswardianta, Farida Huriawati, Nurul Kusuma Dewi \\ IKIP PGRI MADIUN \\ Jl. Setia Budi No.85 Kartoharjo Madiun Jawa Timur \\ frd21pfisae@gmail.com
}

\begin{abstract}
This research is made to knowing the influence of adding amount of seagrass to amount of sand on the compressive strength and the Eco-concrete bricks's water absorbtion. The methods used in this research is experiment with a sample of Eco-concrete bricks $(20 \times 10 \times 6) \mathrm{cm}$ in adding 4 variation amount of seagrass. the first variation is without adding amount of seagrass $(0 \%)$, second adding $5 \%$, third adding $15 \%$, and the fourth is adding $25 \%$. The examination compressive strength and water absorbtion is do to Eco-concrete bricks 28 days age with ten times repetition and take the average number. The result of this examination show the number of compressive strength for each variation are 12,102 $\mathrm{MPa}$ without adding amount of seagrass (0\%), 11,011 $\mathrm{MPa}$ adding $5 \%, 7,6044 \mathrm{MPa}$ adding $15 \%$, and 5,3872 MPa adding $25 \%$. The data for examination of water absorbtion are $12,439 \%$ without adding amount of seagrass ( $0 \%$ ), $13,81 \%$ adding $5 \%, 15,215 \%$ adding $15 \%$, and $16,019 \%$ adding $25 \%$. The conclution is the more concentration adding amount of seagrass the less number of Eco-concrete bricks's compressive strength and otherwise the less concentration adding amount of seagrass the less number of Eco-concrete bricks's water absorbtion power.
\end{abstract}

Keywords: Seagrass, Eco-concrete bricks, compressive strength, water absorption

\begin{abstract}
Abstrak-Penelitian ini dilakukan untuk mengetahui pengaruh penambahan serbuk serasah lamun (seagrass) terhadap pasir pada nilai kuat tekan dan absorbsi air eco-batako.Metode yang digunakan dalam penelitian ini yakni eksperimen dengan sampel eco-batako $(20 \times 10 \times 6) \mathrm{cm}$ dalam 4 variasi penambahan serbuk serasah lamun.Variasi pertama tanpa penambahan serbuk serasah lamun $(0 \%)$, kedua dengan penambahan $5 \%$, ketiga dengan penambahan $15 \%$, dan yang keempat dengan penambahan $25 \%$. Pengujian kuat tekan dan absorbs air dilakukan pada eco-batako umur 28 hari dengan sepuluh kali pengulangan dan diambil nilai rata-ratanya. Hasil penelitian menunjukan nilai kuat tekan untuk setiap variasi adalah 12,102 MPa untuk yang tanpa penambahan serbuk serasah lamun (0\%), 11,011 MPa untuk penambahan 5\%, 7,6044MPa untuk penambahan 15\%, dan 5,3872MPa untuk penambahan $25 \%$. Untuk data pengujian absorsi air adalah $12,439 \%$ untuk yang tanpa penambahan serbuk serasah lamun $(0 \%)$, $13,81 \%$ untuk penambahan $5 \%, 15,215 \%$ untuk penambahan $15 \%$, dan $16,019 \%$ untuk penambahan $25 \%$. Kesimpulan yang diperoleh adalahsemakin banyak konsentrasi penambahan serbuk serasah lamun semakin rendah nilai kuat tekan eco-batako dan sebaliknya semakin sedikit penambahan konsentrasi serbuk serasah lamun dalam eco-batako semakin rendah daya absorbsi airnya.
\end{abstract}

Kata kunci: Lamun, eco-batako, kuat tekan, absorbsi air

\section{PENDAHULUAN}

Pacitan merupakan salah satu kabupaten di Jawa Timur yang memiliki potensi sumber daya alam laut yang luar biasa.Terdapat sekitar 17 pantai di Pacitan dengan karakteristik bervariasi. Pada daerah yang memiliki banyak pantai seperti Kabupatan Pacitan terdapat seresah lamun yang pemanfaatannya belum maksimal.Lamun merupakan salah satu sumberdaya pesisir Indonesia yang bernilai ekologis dan ekonomis. Informasi mengenai ekologi lamun dari wilayah tropis Indo-Pasifik masih jarang, padahal observasi menunjukkan bahwa kekayaan spesies tertinggi ditemukan di wilayah Indo-Pasifik (Erftemeijer dan Herman 1994; Hemminga dan Duarte 2000). Padang lamun di daerah temperate tersusun oleh 1 spesies lamun 
(monospesifik). Sebaliknya padang lamun di daerah tropis mempunyai keanekaragaman lebih tinggi, ada sekitar 11 spesies (Hemminga dan Duarte 2000). Di Indonesia terdapat 13 spesies lamun yang tergolong dalam 7 genus (Nontji 2005). Spesies terkini ditemukan adalah Halophila sulawesii, di kepulauan Spermonde barat daya Sulawesi (Kuo 2007). Di Pacitan, lamun dilaporkan tumbuh antara lain di Pantai Tawang dan Pantai Srau. Distribusi dan stabilitas komunitas lamun ditentukan oleh faktorfaktor antara lain: nutrien, cahaya, sedimen, salinitas, dan suhu (Udy dan Dennison 1997; Ralph et al. 2007; Hemminga dan Duarte 2000; Benjamin et al. 1999; Kahn dan Durako 2006; Masini et al. 1995; Campbell et al. 2006). Lamun merupakan biota laut yang memiliki kadar abu dan selulosa yang tinggi, sehingga juga dapat digunakan sebagai tambahan pada pembuatan batako ringan. Untuk menambah kekakuan pada batako ringan dengan bahan tambahan alternatif dapat ditambah dengan lem kayu yang banyak terdapat di toko-toko bangunan atau lem buatan yang dapat dibuat sendiri, seperti lem yang dibuat dari tepung tapioka atau pati kanji.

'Alasan lain penggunaan bahan seresah lamun untuk bahan campuran beton ringan adalah menciptakan bangunan yang ramah lingkungan (EcoArchitecture) dengan sentuhan teknologi baru untuk daerah pesisir. Dibandingkan dengan batako biasa, batako dengan penambahan seresah lamun ini dimungkinkan mempunyai berat yang lebih ringan, sehingga dapat digunakan pada daerah rawan gempa.Perlu diingat fakta menunjukkan bahwa bangunan adalah pengguna energi terbesar mulai dari konstruksi, bahan bangunan, saat bangunan beroperasi, perawatan hingga bangunan dihancurkan.Menurut Frick Heinz dan Koesmartadi (1999:97) batako mempunyai beberapa keuntungan pemakaian bila dibandingkan dengan bata merah, terlihat penghematan dalam beberapa segi, misalnya setiap $\mathrm{m}^{2}$ luas dinding lebih sedikit jumlah batu yang dibutuhkan, sehingga kuantitatif terdapat penghematan. Apabila dilakukan lifecycle analysis sebuah bangunan akan terlihat berbagai dampaknya terhadap lingkungan dan dapat disimpulkan biaya keseluruhan dari arsitektur yang tidak berkelanjutan adalah jauh lebih tinggi dari yang berkelanjutan (suistainable).

\section{METODE PENELITIAN}

Pelaksanaan penelitian pada bulan Maret sampai dengan bulan September 2016 dan dilakukan di tiga lokasi, yaitu pengambilan bahan baku serasah lamun (seagrass) di pantai tawang dan pantai pidakan Pacitan, proses pembuatan dan perawatan eco-batako dilakukan di Laboratotium Pendidikan Fisika IKIP PGRI MADIUN, dan proses pengujian dilakukan di Laboratorium Bahan Bangunan Fakultas Teknik Departeman Teknik Sipil dan Lingkungan UGM. Pada penelitian ini dibuat satu macam bentuk eco-batako, yaitu berbentuk empat persegi panjang denganukuran : $(20 \times 10 \times 6) \mathrm{cm}$ dengan empat macam variasi penambahan serbuk serasah lamun pengganti pasir. Variasi pertama tanpa penambahan serbuk serasah lamun $(0 \%)$, kedua dengan penambahan $5 \%$, ketiga dengan penambahan $15 \%$, dan yang keempat dengan penambahan $25 \%$.Peralatan yang digunakan dalam penelitian ini adalah cetakan eco-batako berbentuk persegi panjang, mesin uji kuat tekan, gelas ukur, oven, kapiler, scrap, timbangan, dan alat bantu lainnya pada saat pencetakan eco-batako. 


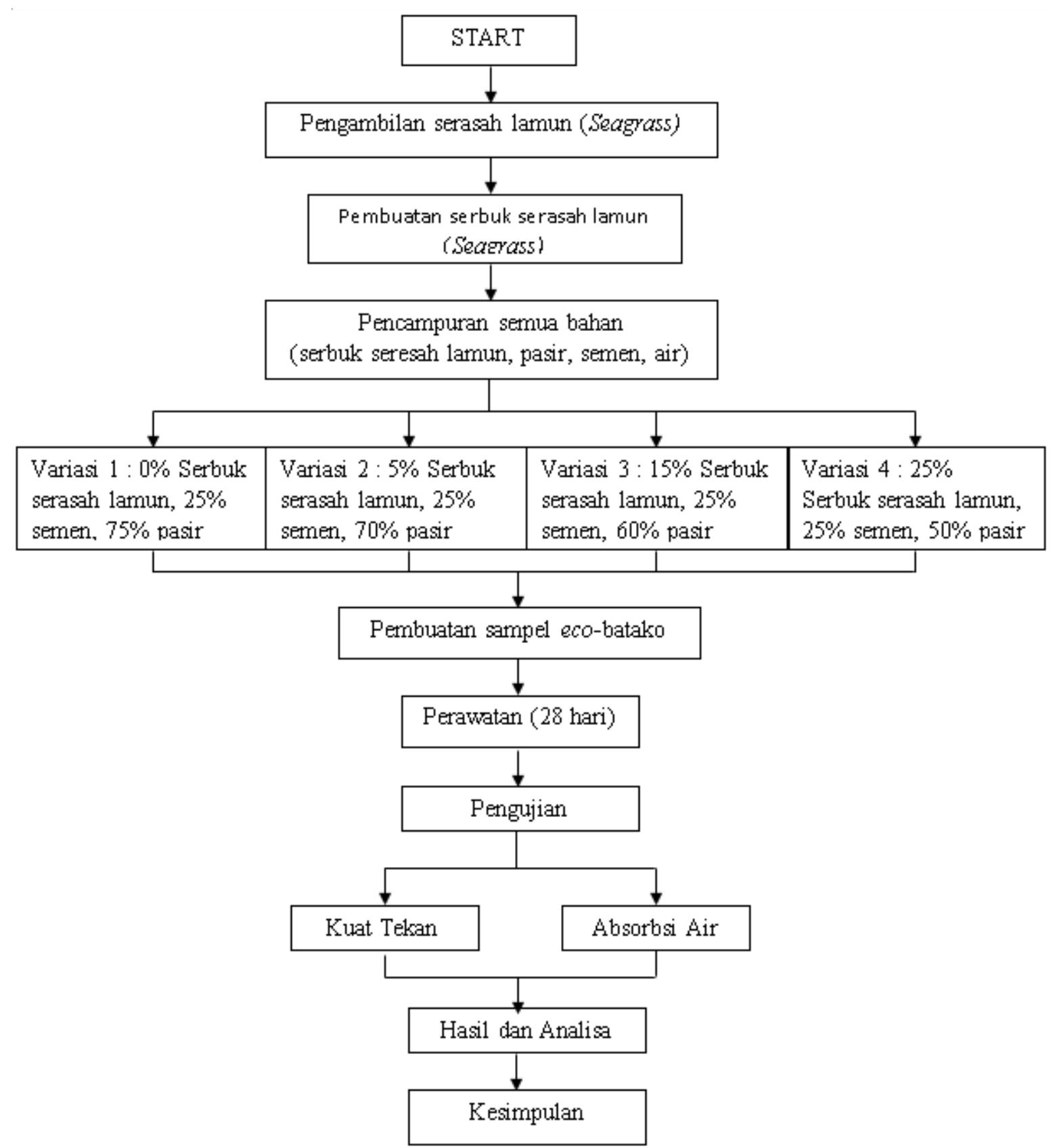

Gambar 1. Diagram Alir Metode Penelitian Pembuatan Eco-Batako

Dalam penelitian ini teknik pengumpulan data dilakukan dengan pengujian langsung di Laboratorium. Adapun pengujian yang dilakukan adalah pegujian meliputi kuat tekan, dan serapan air eco-batako.

1. Prosedur dari pengujian kekuatan tekan dari eco-batako adalah sebagai berikut: Sampel diletakkan pada mesin alat uji tekan dan diatur agar tepat berada ditengah-tengah alat penekan,
Memberikan beban tekan secara perlahan-lahan pada sampel dengan pengatur tuas pompa hingga sampel retak atau hancur, Mencatat nilai beban maksimum yang ditunjukkan oleh jarum penunjuk skala pada saat sampel retak dan hancur. Pencatatan dilakukan saat jarum penunjuk skala tidak lagi bergerak atau bertambah, Mengulangi prosedur $1-3$ terhadap sampel lainnya. Cara pengujian kuat 
tekan batako mengacu pada SNI 030349-1989, yaitu: Pada umur yang telah ditentukan, lakukan pengujian kuat takan pada benda uji dengan rumus sebagai berikut:

Hitungan kuat tekan dengan rumus

$$
\mathrm{f}_{\mathrm{c}}=\frac{P}{A}(\mathrm{MPa})
$$

Ket:

$\mathrm{P}=$ Beban maksimum $(\mathrm{N})$

$\mathrm{A}=$ luas penampang benda uji $\left(\mathrm{m}^{2}\right)$ (Hunggurami, E.,et.al, 2014)

2. Untuk pengujian absorbsi mengacu pada SNI 03-0349-1989, yaitu: benda uji seutuhnya direndam dalam air bersih yang bersuhu ringan, selama 24 jam. Kemudian benda uji diangkat dari rendaman, dan air sisanya dibiarkan meniris kurang lebih 1 menit. Lalu permukaan bidang diseka dengan kain lembab, agar air yang berlebihan di bidang permukaan benda uji terserap kain lembab tersebut. Benda uji tersebut ditimbang (A). setelah itu benda uji dikeringkan di oven dengan suhu $\pm 5^{\circ} \mathrm{C}$, sampai beratnya pada 2 kali penimbangan tidak berbeda lebih dari $0,2 \%$ dari penimbangan yang terdahulu (B). Selisih penimbangan dalam keadaan basah (A) dan keadaan kering (B) adalah jumlah penyerapan air, dan harus dihitung berdasarkan persen berat benda uji kering.

Penyerapan air $(\%)=$

$$
\frac{A-B}{B} \times 100 \%
$$

Ket:

$\mathrm{A}=$ Benda uji dalam keadaan basah

$\mathrm{B}$ = Benda uji dalam keadaan kering (Hunggurami, E.,et.al, 2014)

\section{HASIL DAN PEMBAHASAN}

Pengujian karakteristik eco-batako yang dilakukan dalam penelitian ini meliputi kuat tekan dan absorbsi air. Pengujian kuat tekan dan absorbsi air dilakukan pada umur 28 hari. Pengujian kuat tekan dan absorbs air eco-batako dilakukan dalam sepuluh kali pengulangan dan diambil nilai rataratanya. Hasil pengujian kuat tekan dan pengujian absorbsi air eco-batako ditunjukkan pada Tabel 1 berikut.

\begin{tabular}{|c|c|c|c|c|c|c|c|}
\hline \multirow{2}{*}{$\begin{array}{c}\text { Konsentrasi } \\
\text { Penambahan } \\
\text { Serbuk Serasah } \\
\text { Lamun }\end{array}$} & \multicolumn{3}{|c|}{ Ukuran (mm) } & \multirow{2}{*}{$\begin{array}{l}\text { Umur } \\
\text { (hari) }\end{array}$} & \multirow{2}{*}{$\begin{array}{c}\text { Beban } \\
\text { Maksimal } \\
\text { (kN) }\end{array}$} & \multirow{2}{*}{$\begin{array}{l}\text { Kuat } \\
\text { Tekan } \\
\text { (MPa) }\end{array}$} & \multirow{2}{*}{$\begin{array}{c}\text { Absorbsi } \\
\text { Air (\%) }\end{array}$} \\
\hline & Panjang & Lebar & Tinggi & & & & \\
\hline \multirow{10}{*}{$0 \%$} & 50.2 & 49.7 & 51.2 & 28 & 40 & 16.21 & 11.51 \\
\hline & 50 & 50.1 & 52.3 & 28 & 26.5 & 10.844 & 11.76 \\
\hline & 50.5 & 50.5 & 51.5 & 28 & 40 & 16.238 & 12.44 \\
\hline & 50.1 & 50.1 & 50.1 & 28 & 25.9 & 11.865 & 12.01 \\
\hline & 50.2 & 50.2 & 52.2 & 28 & 37 & 15.122 & 13.4 \\
\hline & 50.1 & 50 & 50.1 & 28 & 38 & 10.719 & 13.24 \\
\hline & 50.1 & 50.1 & 53.1 & 28 & 28,6 & 8.427 & 12.16 \\
\hline & 50.3 & 49.8 & 51.3 & 28 & 31.34 & 10.251 & 12.38 \\
\hline & 50.1 & 50.1 & 52.1 & 28 & 29.7 & 8.141 & 12.58 \\
\hline & 50.1 & 50 & 51.1 & 28 & 32.5 & 13.203 & 12.91 \\
\hline \multicolumn{5}{|c|}{ Rata-rata } & 30.094 & 12.102 & 12.439 \\
\hline
\end{tabular}

Tabel 1. Hasil Pengujian Kuat Tekan dan Absorbs Air 
Bioeksperimen

Volume 3 No.2, (September 2017)

ISSN 2460-1365

\begin{tabular}{|c|c|c|c|c|c|c|c|}
\hline \multirow{2}{*}{$\begin{array}{c}\text { Konsentrasi } \\
\text { Penambahan } \\
\text { Serbuk Serasah } \\
\text { Lamun }\end{array}$} & \multicolumn{3}{|c|}{ Ukuran (mm) } & \multirow{2}{*}{$\begin{array}{l}\text { Umur } \\
\text { (hari) }\end{array}$} & \multirow{2}{*}{$\begin{array}{c}\text { Beban } \\
\text { Maksimal } \\
(\mathbf{k N})\end{array}$} & \multirow{2}{*}{$\begin{array}{l}\text { Kuat } \\
\text { Tekan } \\
\text { (MPa) }\end{array}$} & \multirow{2}{*}{$\begin{array}{c}\text { Absorbsi } \\
\text { Air (\%) }\end{array}$} \\
\hline & Panjang & Lebar & Tinggi & & & & \\
\hline \multirow{10}{*}{$5 \%$} & 50.2 & 49.7 & 51.2 & 28 & 40 & 16.218 & 13.72 \\
\hline & 50 & 50.1 & 52.3 & 28 & 26.5 & 10.874 & 13.56 \\
\hline & 50.5 & 50.5 & 51.5 & 28 & 40 & 16.238 & 12.4 \\
\hline & 50.1 & 50.1 & 50.1 & 28 & 20 & 7.965 & 14.14 \\
\hline & 50.2 & 50.2 & 52.2 & 28 & 37 & 15.122 & 14.49 \\
\hline & 50.1 & 50 & 50.1 & 28 & 19 & 7.719 & 13.84 \\
\hline & 50.1 & 50.1 & 53.1 & 28 & 18 & 7.327 & 14.16 \\
\hline & 50.3 & 49.8 & 51.3 & 28 & 18 & 7.255 & 14.33 \\
\hline & 50.1 & 50.1 & 52.1 & 28 & 20 & 8.141 & 13.54 \\
\hline & 50.1 & 50 & 51.1 & 28 & 32.5 & 13.203 & 13.92 \\
\hline \multicolumn{5}{|c|}{ Rata-rata } & 27.1 & 11.011 & 13.81 \\
\hline \multirow{10}{*}{$15 \%$} & 51.2 & 51.7 & 51.1 & 28 & 19.45 & 9.044 & 14.98 \\
\hline & 50.1 & 52.1 & 52.3 & 28 & 18.31 & 8.416 & 15.76 \\
\hline & 50.3 & 51.5 & 51.5 & 28 & 17.53 & 6.529 & 15.81 \\
\hline & 50.1 & 51.4 & 52.1 & 28 & 12.5 & 7.047 & 14.96 \\
\hline & 50.2 & 52.2 & 52.2 & 28 & 13.42 & 7.979 & 14.88 \\
\hline & 50.1 & 50.9 & 51.5 & 28 & 11.89 & 5.006 & 15.84 \\
\hline & 50.1 & 52.1 & 53.1 & 28 & 13.89 & 6.263 & 14.57 \\
\hline & 50.3 & 51.8 & 51.3 & 28 & 14.97 & 8.717 & 14.64 \\
\hline & 50.3 & 52.1 & 52.1 & 28 & 17.5 & 9.167 & 15.83 \\
\hline & 50.3 & 51.6 & 51.1 & 28 & 12.64 & 7.876 & 14.87 \\
\hline \multicolumn{5}{|c|}{ Rata-rata } & 15.21 & 7.6044 & 15.214 \\
\hline \multirow{10}{*}{$25 \%$} & 50.2 & 50.1 & 52.6 & 28 & 15 & 6.082 & 14.98 \\
\hline & 50.1 & 49.8 & 52.3 & 28 & 13.3 & 5.426 & 14.99 \\
\hline & 50 & 60 & 53.5 & 28 & 12.5 & 5.529 & 14.8 \\
\hline & 50.1 & 51.4 & 55.1 & 28 & 9.5 & 4.047 & 16.96 \\
\hline & 50.2 & 52.2 & 55.2 & 28 & 10 & 4.079 & 14.88 \\
\hline & 50 & 50.9 & 59 & 28 & 9 & 3.686 & 18.84 \\
\hline & 50.1 & 52.1 & 55.6 & 28 & 11 & 6.263 & 18.57 \\
\hline & 50 & 51.8 & 53.2 & 28 & 16.5 & 6.717 & 16.64 \\
\hline & 50.1 & 52.1 & 52.8 & 28 & 17.5 & 7.167 & 14.83 \\
\hline & 50.1 & 51.6 & 54 & 28 & 12 & 4.876 & 14.7 \\
\hline \multicolumn{5}{|c|}{ Rata-rata } & 12.63 & 5.3872 & 16.019 \\
\hline
\end{tabular}

1. Analisa Kuat Tekan Eco-Batako Hasil penelitian menunjukan nilai kuat tekan untuk setiap variasi adalah 12,102 MPa untuk yang tanpa penambahan serbuk serasah lamun $(0 \%), 11,011 \mathrm{MPa}$ untuk penambahan
5\%, 7,6044MPa untuk penambahan $15 \%$, dan 5,3872MPa untuk penambahan $25 \%$. Dari data tersebut dapat dilihat bahwa nilai kuat tekan tertinggi diperoleh dari eco-batako tanpa penambahan serbuk serasah lamun (variasi 0\%) yaitu 12,102 
MPa. Untuk kuat tekan terendah dari eco-batako dengan penambahan serbuk serasah lamun 25\% yaitu 5,3872 $\mathrm{MPa}$. Dari keseluruhan data yang diperoleh menunjukkan bahwa semakin banyak konsentrasi penambahan serbuk serasah lamun semakin rendah nilai kuat tekan ecobatako.Yang menyebabkan penurunan kekuatan tekan dari benda uji ini adalah daya ikat semen terhadap serbuk seresah lamun tidak kuat atau lemah.Hal tersebut diakibatkan oleh serat yang yang dikandung oleh serasah lamun cukup tinggi sehingga menciptakan pori-pori yang banyak dalam eco-batako.Walaupun demikian seluruh variasi sampel ecobatako masih memenuhi criteria batako berdasarkanSNI 03-06911996. Untuk variasi $0 \%$ dan $5 \%$ termasuk mutu $\mathrm{I}$, variasi $15 \%$ termasuk mutu II, dan variasi $25 \%$ termasuk mutu III.

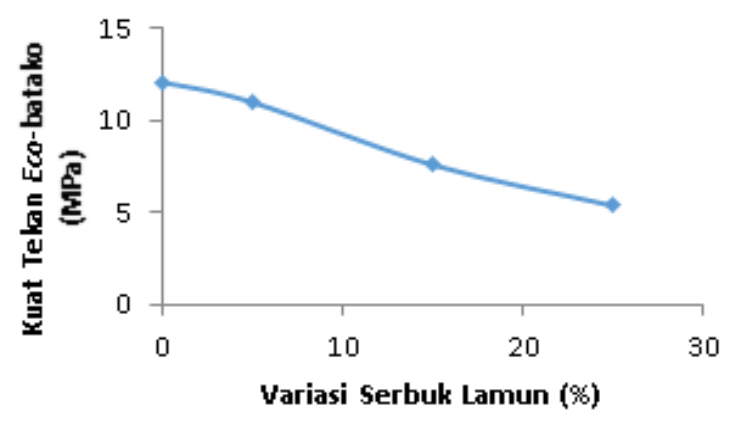

Gambar 2. Grafik hubungan kuat tekan terhadap variasi serbuk lamun pada eco-batako

\section{Analisa Absorbsi AirEco-Batako}

Hasil penelitian menunjukan untuk data pengujian absorsi air adalah $12,439 \%$ untuk yang tanpa penambahan serbuk serasah lamun (0\%), 13,81\% untuk penambahan 5\%,15,215\% untuk penambahan $15 \%$, dan $16,019 \%$ untuk penambahan $25 \%$. Daridata tersebut dapat dilihat bahawa nilai absorbi air tertinggi diperoleh dari eco-batako dengan variasi penambahan serbuk serasah lamun $25 \%$ yaitu $16,019 \%$. Untuk nilai absorbsi air terendah dari eco-batako dengan penambahan serbuk serasah lamun 0\% yaitu $13,81 \%$. Dari keseluruhan data yang diperoleh menunjukkan bahwa semakin banyak konsentrasi penambahan serbuk serasah lamun semakin tinggi persentase kemampuan absorbsi air dari eco-batako. Hal tersebut diakibatkan oleh serat yang yang dikandung oleh serasah lamun cukup tinggi sehingga menciptakan pori-pori yang banyak dalam eco-batako. Berdasarkan SNI 03-06911996tentang bata beton (batako), persyaratan nilai penyerapan air maksimum adalah 25\% (Sumaryanto, D. Satyarno,I. \& Tjokrodimulyo,K. 2009) sehingga seluruh sampel eco-batako masih memenuhi persayaratan stantar nasional batako atau bata pejal.

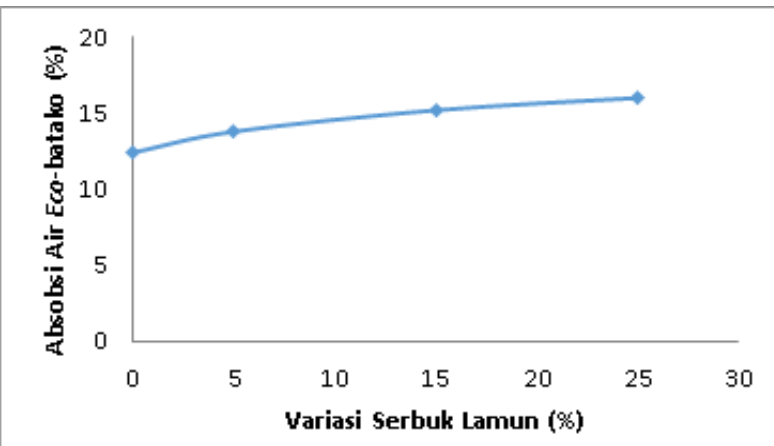

Gambar 3. Grafik hubungan absorbsi air terhadap variasi serbuk lamun pada $e c o$-batako

\section{KESIMPULAN}

Dari hasil analisa dan pembahasan yang dilakukan terhadap sampel berupa eco-batako dengan variasi penambahan serbuk serasah lamun dapat disimpulkan:

1. Hasil penelitian menunjukan semakin banyak konsentrasi penambahan serbuk serasah lamun semakin rendah nilai kuat tekan eco-batako dan sebaliknya semakin sedikit penambahan konsentrasi serbuk serasah lamun dalam eco-batako semakin rendah daya absorbsi airnya.

2. Hasil penelitian menunjukan bahwa dengan menggunakanpenambahan 
serbuk serasah lamun sebagai pengganti pasirterhadap kekuatan dan ketahananeco-batako dengan tetap memperhatikan komposisi campuran.

3. Dari hasil penelitian menunjukan bahwa berdasarkan SNI 03-06911996 ntuk variasi $0 \%$ dan $5 \%$ termasuk mutu I, variasi $15 \%$ termasuk mutu II, dan variasi $25 \%$ termasuk mutu III.

4. Seluruh sampel eco-batako memiliki nilai absorbsi air dibawah $25 \%$ sehingga masih memenuhi persayaratan stantar nasional batako atau bata pejal.

\section{SARAN}

Dari penelitian yang telah dilakukan terhadap pembuatan eco-batako dengan bahan tambahan serbuk serasah lamun maka dapat diberikan saran sebagai berikut:

1. Perlu adanya penelitian lebih lanjut dengan persentase yang bervariasi mengenai penggunaan serbuk serasah lamun sebagai bahan tambah dan pengurangan pasir dalam pembuatan eco-batako sehingga memberikan pengaruh terhadap kuat tekan dan absorbsi air.

2. Perlu pembuatan benda uji atau sampel yang lebih banyak, supaya data yang dihasilkan lebih akurat.

\section{DAFTAR PUSTAKA}

Benyamin Lakitan. 2004. Dasar-dasar Fisiologi Tumbuhan: Raja Grafindo Persada.

Campbell, S. J., L. J. McKenzie, S. P. Kerville. 2006. Photosynthetic responses of seven tropical seagrasses to elevated seawater temperature. Journal of Experimental Marine Biology and Ecology 330: 455468
Erftemeijer, P. L. A. and P. M. J. Herman. 1994. Seasonal changes in environmental variables, biomass, production and nutrient contents in two contrasting tropical intertidal seagrass beds in South Sulawesi, Indonesia. Oecologia 99: 45-59

Frick. H, 1999, Ilmu Konstruksi Bangunan I, Penerbit Kanisius : Yogyakarta.

Hemminga, M. A., and C. M. Duarte. 2000. Seagrass ecology. Cambridge University Press

Hunggurami, E, Wilhelmus B, Richardo Y, 2014.Studi Eksperimen Kuat Tekan dan Serapan Air Bata Ringan CLC dengan Tanah Putih sebagai Agregat. Jurnal teknik Sipil Volume 3 Nomor 2 Undana

Kahn, A. E., and M. J. Durako. 2006. Thalassia testudinum seedling responses to changes in salinity and nitrogen levels. Journal of Experimental Marine Biology and Ecology 335: 1-12

Kuo, J. 2007. New monoecious seagrass of Halophila sulawesii (Hydrocharitaceae) from Indonesia. Short communication.Aquatic Botany 87: 171-175

Masini, R. J., J. L. Cary, C. J. Simpson, A. J. McComb. 1995. Effects of light and temperature on the photosynthesis of temperate meadow-forming seagrasses in Western Australia. Aquatic Botany 49: 239-254

Nontji,A.2005.LautNusantara.Djambatan, Jakarta

Ralph, P. J., M. J. Durako, S. Enriquez, C. J. Collier, M. A. Doblin. 2007. Impact of light limitation on seagrasses. Journal of Experimental Marine Biology and Ecology 350: 176-193 
Bioeksperimen

SNI-03-3349-1996.Tata Cara Pembuatan Rencana Campuran Beton Normal. Pustran, Balitbang,

Departmen Pekerjaan Umum.

Udy, J. W., and W. C. Dennison. 1997. Growth and physiological responses of three seagrass species to elevated sediment nutrients in Moreton Bay, Australia. Journal of Experimental Marine Biology and Ecology 217: 253277 